\title{
Effects of Dual-Credit Enrollment and Early College High School on Utah Public Education
}

\author{
Richard E. Haskell, Sr, PhD. ${ }^{1}$ \\ ${ }^{1}$ Bill and Vieve Gore School of Business, Westminster College, Salt Lake City, Utah, USA \\ Correspondence: Richard E. Haskell, Sr., PhD, Bill and Vieve Gore School of Business, Westminster College, Salt Lake \\ City, Utah, USA. Tel: 1-801-832-2600.
}

Received: January 21, 2016

Accepted: February 1, 2016

Available online: February 4, 2016

doi:10.11114/aef.v3i2.1323

URL: http://dx.doi.org/10.11114/aef.v3i2.1323

\begin{abstract}
This study considers the effects of Dual-Credit Enrollment (DCE) and Early College High School (ECHS) programs on the Utah's 2008 and 2009 public high graduation cohorts via an examination of the Utah Data Alliance longitudinal public education dataset. The study assesses high school graduation rates, dual course credits earned, higher education enrollment, time-to-completion, and graduation outcomes with a focus towards how these accelerated learning programs effect the student household and state, specifically, and public education finance, generally.

As participation in dual-credit programs is voluntary and by self-selection, the study employs Propensity Score Matching method (PMS) as a quasi-experimental design methodology in an effort to limit the endogeneity bias present in such non-experimental data. Although PMS offers many advantages, its strength as an estimator is dependent on the existence of complete and quality matching variables. To assure accurate model specifications given the available data, Receiving Operator Characteristic (ROC) Analysis is applied to variations on the PMS models.

Estimated outcomes reflect positive effects for the examined student populations differentiated by program participation, with the strongest outcomes arising from ECHS participation. The economic effects of accumulating higher education course credits and decreases in higher education time-to-completion may yield the most interesting outcomes, enjoy the strongest causal claims, and result in measurable household and state level savings. These outcomes may also reveal potential weakness in the structure of higher education course and major programming, and the difficulty presented as high school students make higher education decisions.
\end{abstract}

Key words: education finance, dual credit enrollment, concurrent enrollment, public education, Utah, early college high school, propensity score matching, receiver operating characteristics

\section{Introduction}

In response to concerns with respect to suboptimal secondary and higher education outcomes, dual-credit enrollment ${ }^{1}$ programs have become widely popular in the United States (Berger et al, 2013; Edmunds et al, 2010; Kleiner \& Lewis, 2005; Martinez \& Bray, 2002). These programs, falling under the general category of accelerated learning program, allow public high school students to enroll in college level courses via concurrent enrollment, early enrollment or advanced placement, and provide high school and higher education course credit based on successful course completion and the requirements of the receiving higher education authority. (Bailey \& Karp, 2003; Boswell, 2001; Greenberg, 1988). Such programs have proven effective in easing the transition between high school and college generally and motivate improvements in secondary and higher education outcomes (Harnish, 2005; Vargas, 2013; Whitaker, 2011). In most areas participation relies on self-selection, though the benefits of participation are observable, statistically

\footnotetext{
${ }^{1}$ Note the differentiation of the terms Dual-Credit Enrollment (DCE) and dual-credit enrollment. The term Dual-Credit Enrollment is used in this study to denote those students who participated in dual-credit courses providing both secondary and higher education course credit while enrolled in a traditional public high school. This is differentiated from dual-credit enrollment, which simply denotes those students who participated in any type of dual-credit course programs, either Dual-Credit Enrollment or Early College High School, while enrolled in public high school.
} 
significant, and positive (Swanson, 2008; Taylor, 2013).

Such accelerated learning programs have further been seen as potential contributors to solving persistent higher education time-to-degree-completion problems, and the financial burdens increasing higher education costs place on students, their households, and state budgets (Appleby et al, 2011). Dual-credit enrollment, as a subset of accelerated learning, provides significant higher education time and cost improvement; reducing household pressures with respect to debt financing of higher education expense (Haskell, 2016; Rothstein \& Rouse, 2011; Serdyukov, 2008). Underrepresented student households experience yet greater improvement than do their general student population counterparts with respect to such outcomes, providing particular benefit to economically brittle students during their academic and early-labor market careers (Haskell, 2016; Rothstein \& Rouse, 2011).

DCE differs from ECHS in that DCE is motivated by a student's choice to participate in dual-credit courses while attending their traditional high school, often referred to as the student's boundary school. ECHS participants attend public high school without respect to district or school-level boundaries in a facility dedicated to maximizing dual-credit course enrollment, often located on or near a public higher education campus. ECHS offers a structure through which students are focused towards earning a substantial number of higher education credits while in high school, often sufficient to earn an Associate's Degree, rather than earning a limited number of higher education credits. Wherever possible, high school courses required for graduation are substituted with concurrent enrollment, early enrollment and advanced placement courses taught at the high school or affiliated college. Where ECHS students choose to earn an Associate's degree coincident with receiving their high school diplomas, several additional college level courses are required (Edmunds et al, 2010; Nakkula, Richard \& Ongaga, 2011; Nodine, 2009). Depending on the student's preferred course selection, these courses may be taken at the ECHS as additional concurrent enrollment courses, while others may be taken as early enrollment at the affiliated college. Both DCE and ECHS programs provide a head start towards college completion at the expense of the state's public education system and without greater burdens on that system or those households supporting it (Fincher-Ford, 1996; Karp \& Hughes, 2008; Lieberman, 2004; Welsh et al, 2005).

Numerous studies support positive outcomes for participants in DCE and ECHS programs (Karp et al, 2007; Kim \& Bragg, 2008; Speroni, 2011; Struhl \& Vargas, 2012; Swanson, 2008), but access to individual level student data with sufficient detail to separate the effects of DCE and ECHS has been limited, and the ability to connect outcomes to household and state finances has been similarly challenging. Of those studies seeking to yield such clarity and connection, few employ statistical methods sufficient to infer causality and to credibly estimate their effects (An, 2009; Speroni, 2011; Struhl \& Vargas, 2012; Taylor, 2013).

Data collected through the National Education Longitudinal Study of 1988 (NELS:88) ${ }^{2}$ and Education Longitudinal Study of 2002 (ELS:2002) ${ }^{3}$ has been insufficient to separate the effects of DCE and ECHS and until recently state level education data bases have been limited. The American Recovery and Reinvestment Act of 2009 (ARRA 2009) included funding to develop state level education longitudinal data sets ${ }^{4}$ with sufficient detail as to support a detailed, individual level analysis of dual credit enrollment programs. Of the 50 states applying for these funds 20 were awarded grants: Utah was among those 20 state states.

The formation of the Utah Education Policy Center ${ }^{5}$ and Utah Data Alliance ${ }^{6}$, with funding available through ARRA

2 The National Education Longitudinal Study (NELS:88) is a survey of eighth grade students, first surveyed in 1988 with follow up surveys in 1990, 1992, 1994 and 2000, on a range of topics including school, work, and home experiences; educational resources and support; the role in education of their parents and peers; neighborhood characteristics; educational and occupational aspirations; and other student perceptions. https://nces.ed.gov/surveys/nels88/

${ }^{3}$ The Education Longitudinal Study of 2002 is a nationally representative, longitudinal study of 10th graders in 2002 and 12th graders in 2004 following students throughout secondary and postsecondary years and includes survey data from students, parents, teachers and school administrators. Data collection includes waves in 2002, 2004, 2005, 2006, 2012 and 2013. https://nces.ed.gov/surveys/els2002/

${ }^{4}$ The Institute of Education Sciences, funded through the American Recovery and Reinvestment Act of 2009, awarded grants to 20 state education departments for the design and implementation of statewide longitudinal data systems. https://nces.ed.gov/programs/slds/fy09arra_announcement.asp

5 The Utah Education Policy Center (UEPC) is an independent, nonpartisan University of Utah research center in the College of Education that bridges research, policy, and practice for Utah public schools and higher education (www.uepc.utah.edu). The center houses the Utah Data Alliance and other research and policy based projects.

${ }^{6}$ Data for this research was accessible through Utah's state longitudinal data system database administered by the Utah Data Alliance (UDA) which includes data supplied by UDA partners and the StudentTracker service from the National 
2009 and the Utah Legislature $\left(2014^{7}\right)$, facilitated the compilation of a longitudinal data set of Utah public education data sufficiently rich to examine the effects of DCE and ECHS on targeted secondary and higher education outcomes. The data includes individual level student data from the Utah State Office of Education (USOE), Utah System of Higher Education (USHE), Utah College of Applied Technology (UCAT) and Utah Department of Workforce Services (UTDWS) inclusive of public education enrollment, performance, and completion data, and limited demographic, labor market and income data.

This study represents the first examination of this data set by a researcher outside of the UEPC, the UDA and its stakeholders. The study employs Propensity Score matching (PSM) to measure DCE and ECHS's effects on selected outcomes as the method provides a methodologically sound alternative to linear regression modeling applicable to social science research (Austin, 2011; Dehejia \& Wahba, 2002; Peikes, Moreno \& Orzol, 2012; Rosenbaum \& Rubin, $1983,1984 \& 1985)$. To assure the accuracy of the selected models, receiver operating characteristic (ROC) analysis is employed as a post estimation tool.

This study includes available demographic and public education enrollment and performance data for Utah's public high school graduation cohorts of 2008 and 2009 and considers the effects of participation in DCE and ECHS programs as treatments on subject student populations. These effects are estimated for secondary education performance (ACT scores) and graduation, dual course credits earned ${ }^{8}$, post-secondary higher education enrollment, and higher education time-to-completion and degree attainment outcomes. Traditional high school students (TRAD) are used as the control, or non-treated, group. PSM and ROC analytics are employed to estimate the average effects of these treatments on the treated, from which a discussion of potential economic and social impacts leads to the consideration of public policy issues and their resulting household endowments.

\section{Dual-Credit Enrollment and Early College High School programs in Utah}

Dual credit course offerings have been in available in Utah's public high school system since the mid-1970s, with each of the state's 138 public high schools offering dual credit curriculum as of the 2015 academic year. In 2006 USOE and USHE actively encouraged and supported the development of Utah's early college high schools with the express purpose of serving underrepresented students. By 2008 six such high schools opened on or near public college campuses ${ }^{9}$; by the 2016 academic year eight ECHS campuses will be in operation. In 2012 Utah's ECHSs graduated 781 students out of 32,884 high school graduates throughout the state (USOE, 2013), barely 2.3\% of the cohort. These schools enjoyed a dropout rate of less than $2 \%$ compared to a state dropout rate of $12 \%$ for the year, and a dropout rate of over 7\% for the state's other dual-credit enrollment students (USOE, 2013).

Dual-credit enrollment programs in Utah are required to follow guidelines established by the Utah State Legislature inclusive of the program's purpose, student eligibility, school and student participation, credit transfer, the program's fiscal attributes. Utah's express purpose for offering dual-credit courses is to "provide a challenging college-level and productive secondary school experience, particularly in the senior year, and to provide transition courses that can be applied to post- secondary education" (UAR R277-713, pg. 2). Like most states, Utah includes eligibility standards for dual-credit participation consistent with those of the higher education institution offerings the course(s).

Students selecting participation in Utah ECHS apply for a limited number of openings each year with acceptance based on interviews and completion of an entrance examination, the requirements for which are no different than those required for advancing from one grade to another in the broader Utah secondary education environment; the charters for each of these schools specifies preference to be extended underrepresented students ${ }^{10}$. Utah's ECHS students receive per pupil funding from state and federal sources at the same levels as their traditional public high school counterparts, require no additional individual or household contributions, and higher education tuition for the credit hours earned is paid out of the school's allocated state and federal funds (UAR R277-713, pg. 3).

Student Clearinghouse. This research including the methods, results, and conclusions neither necessarily reflect the views nor are endorsed by the UDA partners. All errors are the responsibility of the author.

${ }^{7}$ Utah Senate Bill 0034 (March 2014) provided ongoing funding for the Utah Data Alliance and Utah Education Policy Center http://le.utah.gov/ 2014/bills/static/SB0034.html

${ }^{8}$ The term dual course credits in this study includes higher education credits earned through concurrent enrollment, early enrollment, and advanced placement courses.

${ }^{9}$ Utah's six Early College High Schools as of 6/30/2014: Academy for Math, Engineering and Science (AMES); Intech Collegiate High School; Itineris Early College High School; Northern Utah Academy for Math, Engineering and Science (NUAMES); Success Academy; and Utah County Academy of Sciences (UCAS).

${ }^{10}$ Charters for each of Utah's Early College High Schools are available through the Utah State Charter School Board, a unit within the Utah State Office of Education:

http://www.schools.utah.gov/CURR/earlycollege/Early-College-High-School.aspx 
Funding for Utah's dual-credit courses is provided largely through funds allocated by USOE ${ }^{11}$ based on student higher education credit hours earned with amounts differing for concurrent enrollment, early enrollment and advance placement courses. For the 2014 academic year ending June $30^{\text {th }}$, Utah public education allocated less than $\$ 6.9$ million for dual-credit enrollment out of more than $\$ 2.9$ billion provided those public high schools offering such courses; less than $0.24 \%$. When broken down by type of high school, the state's 2014 allocation memo shows that traditional high schools offering dual-credit courses were budgeted to receive $0.38 \%$ of their funds for the support of these students/courses, non-ECHS schools were allocated $0.21 \%$ and ECHS's were allocated $3.56 \%$ of their budget in support of dual-credit courses. The significant difference between ECHS and others reflects the mission and purpose of these schools with respect to the number of higher education credit hours their students are designed to accumulate.

Where dual-credit courses are offered through the traditional or charter high school that is not an early college high school, student households may be assessed fees as allowed by the Utah Administrative Rule. For those students enrolled in a traditional high school, policies regarding who pays the allowable fees differ by district, with student households being required to pay much or all of the allowable fees. Courses required for high school graduation taken through one of Utah's six ECHS's are provided without added cost to the student household; the high school's budget bearing the expense. Non-dual-credit enrollment college courses taken by ECHS students, which also fulfil high school course requirements and are necessary for high school graduation, such as some science or STEM courses, are paid for by the ECHS out of its state allocated revenues.

Where these courses are taken by ECHS students for the purpose of earning sufficient higher education course credits to receive an Associate's degree coincident with earning their high school diploma, the student household is often required to bear the higher education tuition expense as agreed upon by the ECHS and the affiliated college. Students who earn sufficient credits to receive an Associate's Degree often pay upwards of $\$ 1,000$ in higher education costs in order to do so, a modest expense compared with an average two-year in-state tuition cost of $\$ 8,640^{12}$ required by Utah's public colleges and universities for sufficient credit hours to earn an Associate's degree. Just as with most other forms of higher education, those households unable to afford the additional higher education expenditure find it may be financed by federal student loans or other student financial aid programs.

\section{Utah Public High School and Higher Education Students ${ }^{13}$}

Utah's public education high school graduation cohorts of 2008 and 2009 include 45,214 and 45,328 students respectively. Of the 90,642 students in the combined cohorts, $65.2 \%$ received a high school diploma in the prescribed time frame. This differs from the $88 \%$ graduation rate for 2008 and 2009 published by the state as the data compiled in the Utah Education Longitudinal data set complies with the US Department of Education's cohort graduation requirements, rather than the state's more generalized and often cited graduation rate (USOE 2013). Of the combined cohorts, 52\% are male, $48 \%$ female, $21 \%$ minority, $41 \%$ low income, and $12 \%$ English Language Learners. Low-income male and female students, $21 \%$ and $20 \%$ respectively, accounted for 37,127 students. While minority male and female students represented $11 \%$ and $10 \%$, totaling 18,978 students. The distributions change when differentiated by treatment with participation in ECHS representing just $1.1 \%$ of the combined high school graduation cohorts and DCE representing $36.7 \%$.

The measures for dual course credits differ only marginally for minority, low income, and ELL DCE participants with a high of 9.51 and low of 9.15 in the subject student groups, though these levels are lower than those observed in the general student population regardless of gender (Figure $1^{14}$ ). Low income DCE participants accumulated slightly more dual course credits than did their minority student group counterparts with minority females accumulating the fewest number of credits at 9.15. ECHS participants accumulate dual course credits at a higher level than do DCE participants, as might be expected. ECHS participants also experienced a wider range of credit accumulation, from a low of 13.61 to a high of 16.16 in the various minority, low income and ELL student groups. Again, those in the subject student groups tend to accumulate fewer credits than their general student polulation peers. Low income males tended to accumulate the highest number of credits at 15.98 with minority students accumulating 13.98 credits.

${ }^{11}$ Figures derived from Utah State Office of Education Allocation Memo, Minimum School Program Monthly Allotment for Fiscal Year 2014, Utah State Office of Education, pp. 1-352, April 21, 2014

${ }_{12}$ Annual tuition costs for full time students enrolled in one of the eight public colleges in the Utah System of Higher Education (USHE) average $\$ 4,320$ for in-state students, with a range from $\$ 2,830$ (Snow College) to $\$ 6,511$ (University of Utah). College Tuition Comparison Summary Table offered by College Tuition Compare: http://www.collegetuitioncompare.com/compare/tables/?state=UT\&type=Public

${ }^{13}$ Data collected through the Utah Data Alliance longitudinal dataset for the Utah publish high school graduation cohorts of 2008 and 2009. Appendix C: Descriptive Statistics: www.richardhaskell.net/resources/Appendix+C+-+Descriptive+Statistics.pdf

${ }^{14}$ Figure 1: Utah Data Alliance; 2008 \& 2009 Public High School Graduation Cohorts, 2013 data release 


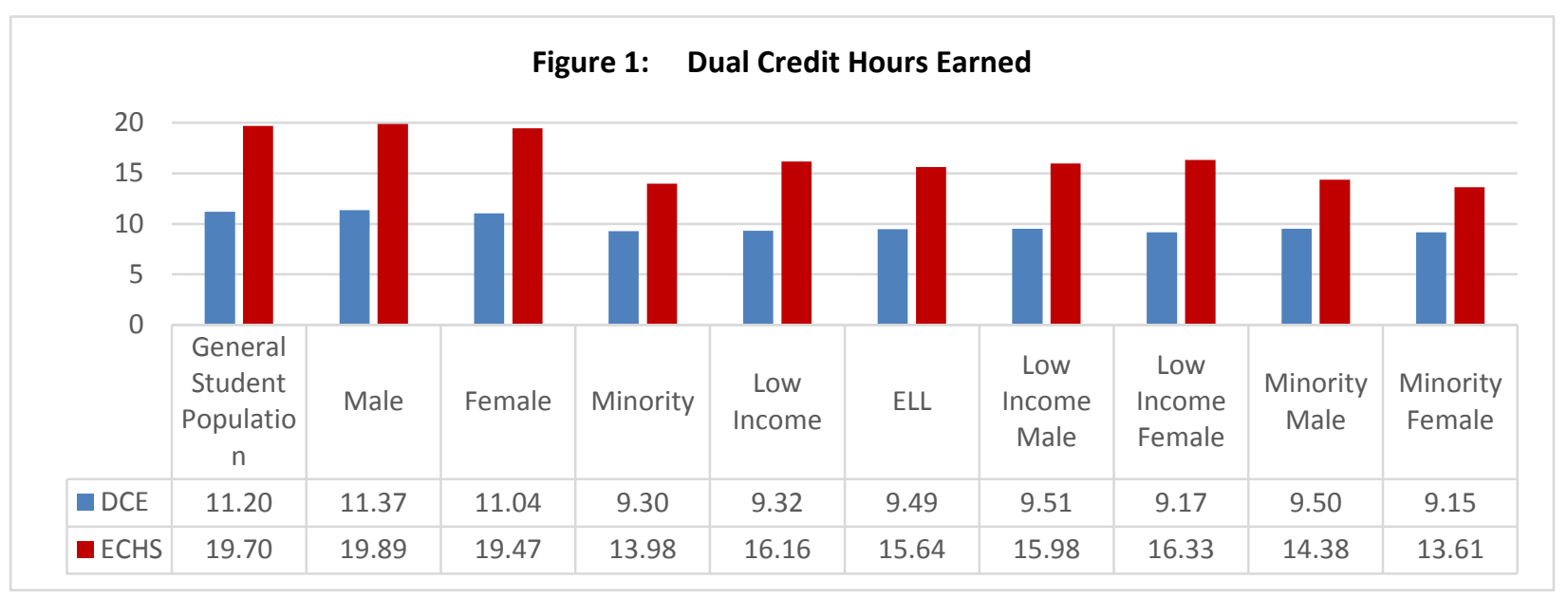

The conversion ratio for concurrent enrollment credit hours earned versus those attempted suggests an interesting relationship in this study (Figure $2^{15}$ ). Unlike the dual course credit meaure, this does not include advanced placement course credits as successful completion of advanced placement courses result in varying levels of higher education credits granted based on the guidelines of the college or university at which the student seeks to apply them. Concurrent and early enrollment course credits in Utah public education are earned as higher education credits from the Utah System of Higher Education (USHE), and provided equal credit at any of Utah's public colleges and universities. DCE participants experience credit conversion at $83.2 \%$ in the general student population, a level equalled by the minority female student populatoin and only minimally different than each of the measured groups. By contrast, ECHS participants in the general student population average $86.2 \%$ concurrent enrollment course credit conversion, a level $6.4 \%$ higher than the lowest underrepresented student group measured.

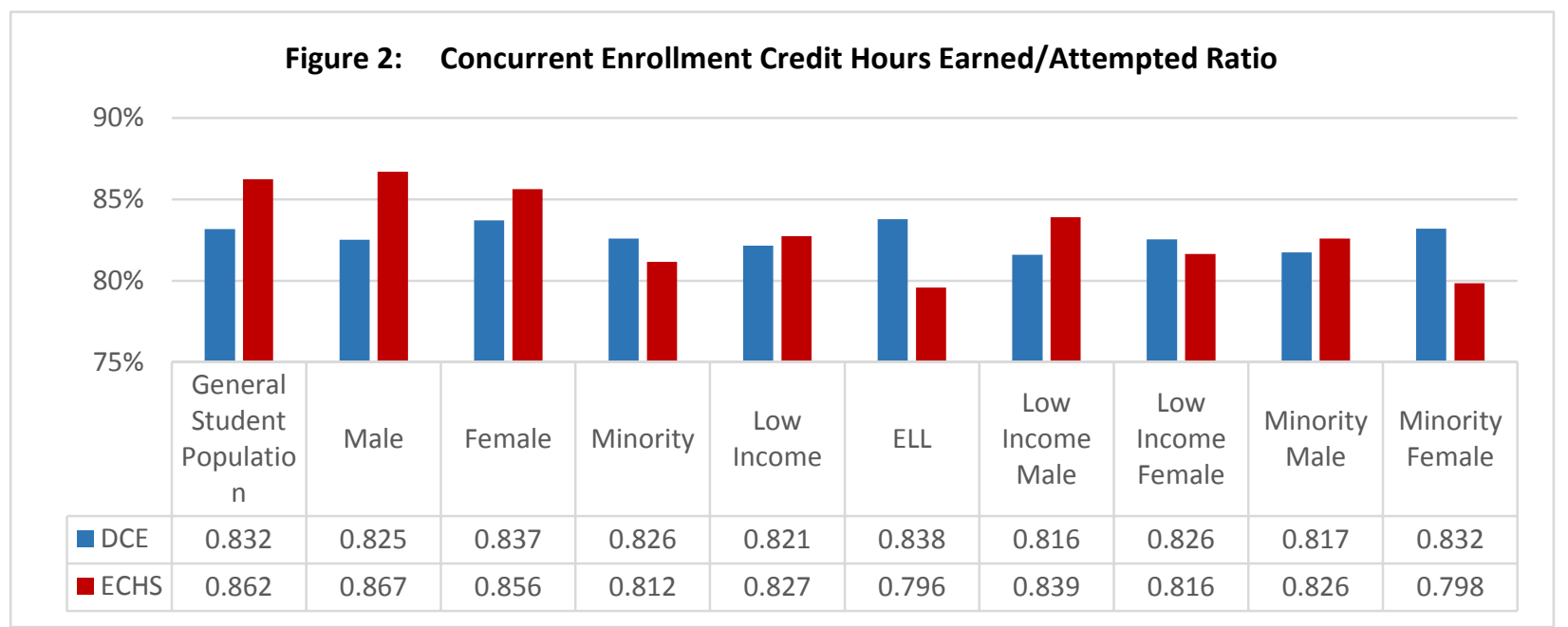

While high school enrollment and graduation present near even male/female distribution, low income, minority, and ELL student group graduation rates are sharply lower than those in the general student populations (Figure $3{ }^{16}$ ). Where $63 \%$ of males graduated from high school, $48 \%$ and $42 \%$ of low income and minority males graduated. Similar disparities can be seen in the female student population with minority and low income females graduating at sharply lower rates than for females in the general student population.

15 Figure 2: Utah Data Alliance; 2008 \& 2009 Public High School Graduation Cohorts, 2013 data release

${ }^{16}$ Figure 3: Utah Data Alliance; 2008 \& 2009 Public High School Graduation Cohorts, 2013 data release 


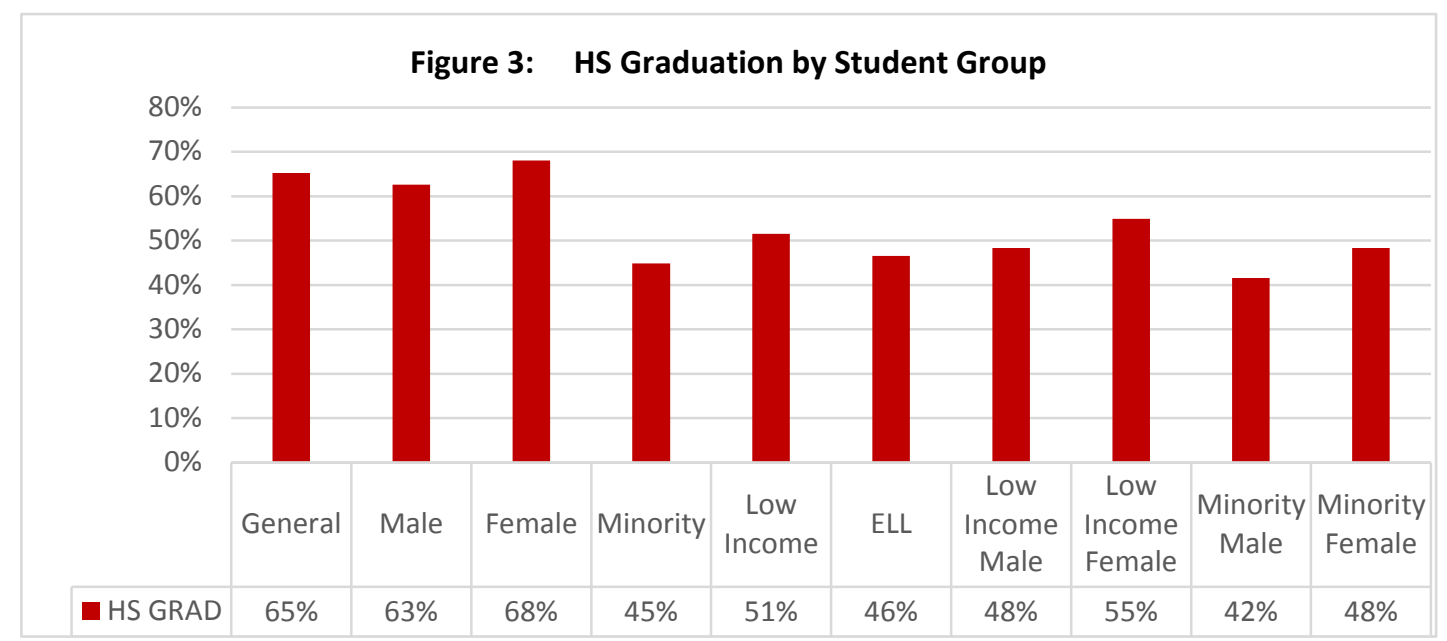

Utah higher education enrollment figures for the subject cohorts show meaningfully lower rates of enrollment for low income and minority student groups for both Utah public higher education as well as higher education generally (Figure $4^{17}$ ). English language learners have one of the lowest rates of higher education enrollment, with only $38 \%$ of ELL students enrolling in higher education, and have a dramatically reduced rate of enrollment in Utah public higher education (3\%). Though low income and minority males and females enroll in higher education at a rate roughly $15 \%$ lower than their general population counter parts, their enrollment in Utah public education is otherwise relatively consistent at $8-9 \%$ less than higher education enrollment generally. The gap between higher education enrollments in Utah public education versus higher education generally is heavily influenced by the presence of Brigham Young University, a private institution affiliated with Utah's dominant religious group, the Church of Jesus Christ of Latter-Day Saints (LDS).

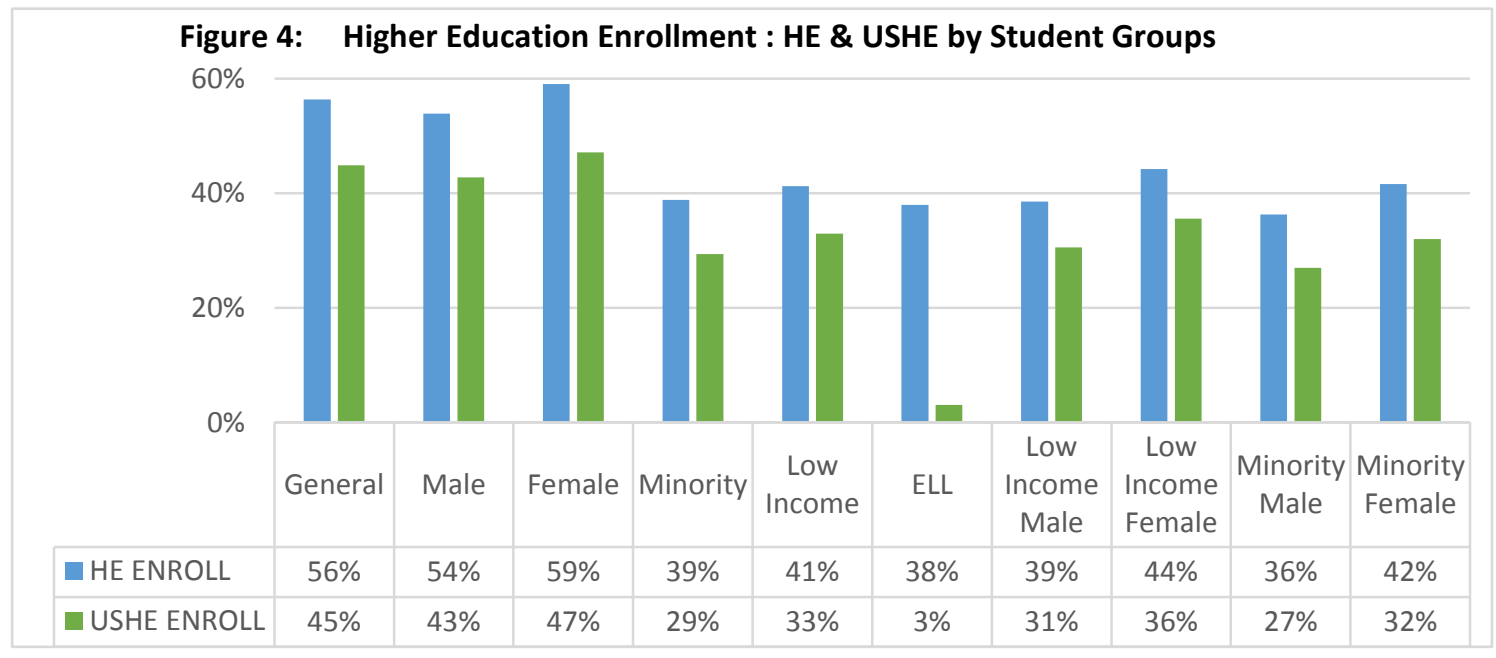

Higher education graduation figures represent the percentage of the respective student groups having completed a higher education degree or certificate program (Figure $5^{18}$ ) The data used in this study includes post-secondary higher education through the 2013 academic year update and represents five and four years of higher education data for the 2008 and 2009 cohorts, respectively. Higher education graduation data shows minority and low income graduation levels lower than that of their respective peer groups. Male and female disparities are relatively consistent among student groups, though male graduation rates lagging female rates by as much as $50 \%$, proportionately. This may also be influenced by student religious affiliation as some Utah males in the subject cohorts as a result of the voluntary

17 Figure 4: Utah Data Alliance; 2008 \& 2009 Public High School Graduation Cohorts, 2013 data release

${ }^{18}$ Figure 5: Utah Data Alliance; 2008 \& 2009 Public High School Graduation Cohorts, 2013 data release 
mission experience many of these males experience with the LDS $\operatorname{church}^{19}$.

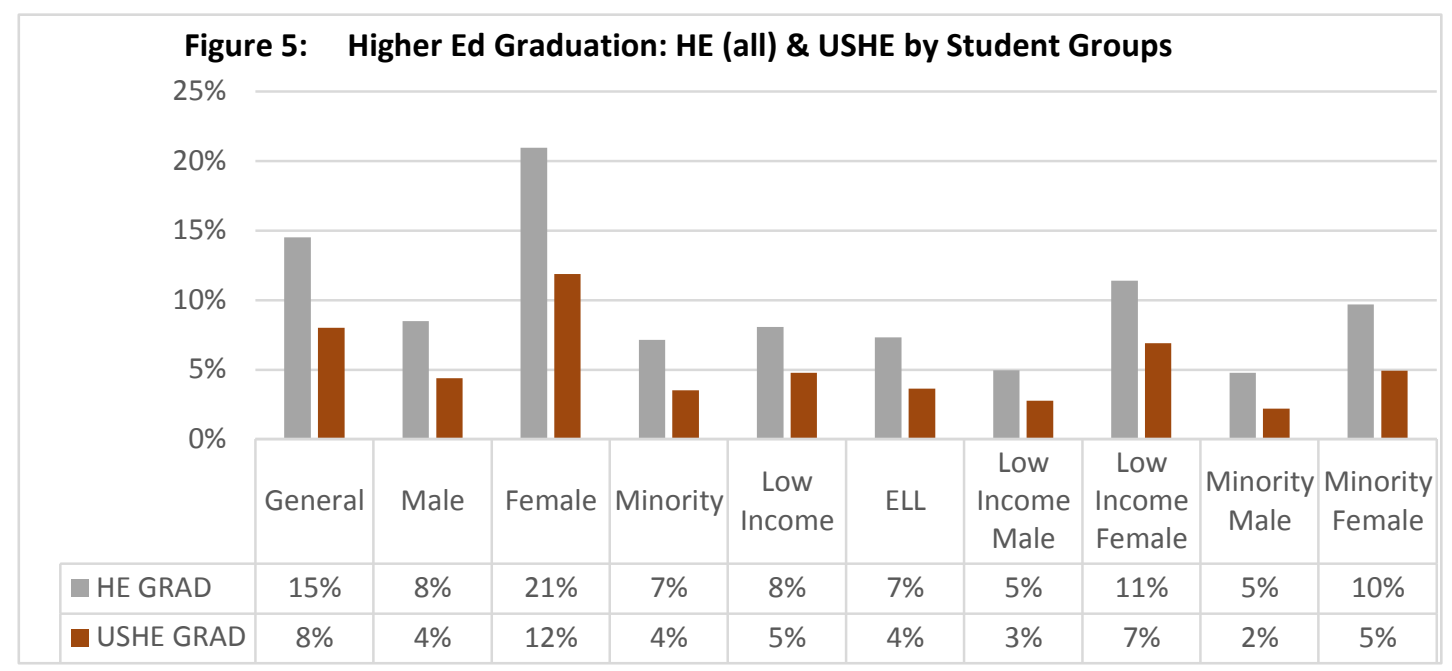

Measures of higher education degree attainment (Associate and Bachelor's) are calculated as a percentage of those successfully completing a higher education degree. As would be expected given the period for which data is included, Bachelor's degree attainment lags that of an Associate's degree, which difference may change or even be reversed with additional years of higher education participation (Figure $6^{20}$ ). The relatively high level of Associate's degree attainment among the cohorts is also influenced by the high number of these degrees earned by ECHS students; 786 of the 6,554 among the subject cohorts.

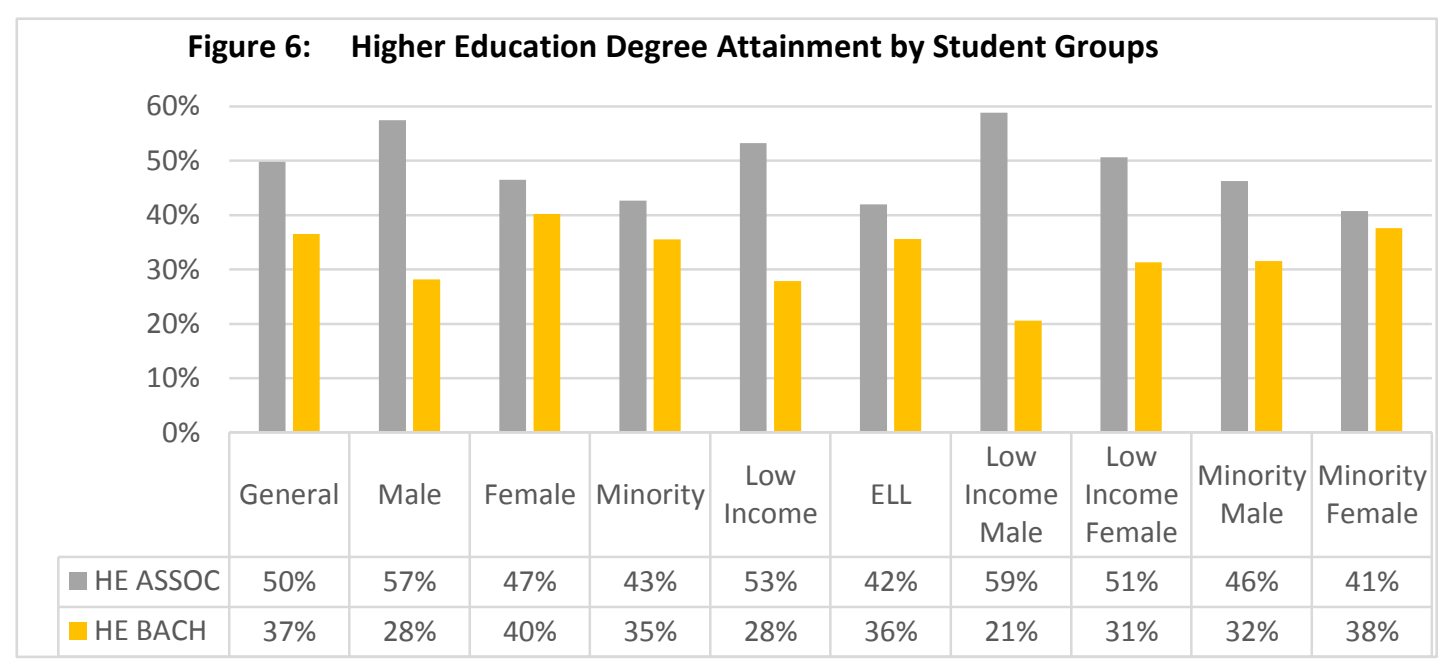

Time-to-completion in this study is measured as the days to degree completion (Associate or Bachelor's) from June $1^{\text {st }}$ of each cohort's high school graduation year. There is little difference among the various student groups for each degree type measured with an average time-to-completion of 947 and 1,549 days for Associate and Bachelor's degrees, respectively, among the various minority and low income student groups. This differs from their respective peers among the general student population by approximately one to two months (Figure $7^{21}$ ).

Decreases in time-to-completion, motivated by increased higher education course credit accumulation while in high school, are directly linked to decreases in household and state higher education costs as students decrease tuition and semester living expenses. Such decreases also open up higher education seats other students are then allowed to fill.

${ }_{19}$ Many LDS males voluntarily postpone or take leave of higher education for a period of two years between the ages of 18-22 years old. Prior to the 2013-2014 academic year LDS females participation in such voluntary service began at age 21 and likely provides limited impact on the subject cohorts.

${ }^{20}$ Figure 6: Utah Data Alliance; 2008 \& 2009 Public High School Graduation Cohorts, 2013 data release

${ }^{21}$ Figure 7: Utah Data Alliance; 2008 \& 2009 Public High School Graduation Cohorts, 2013 data release 


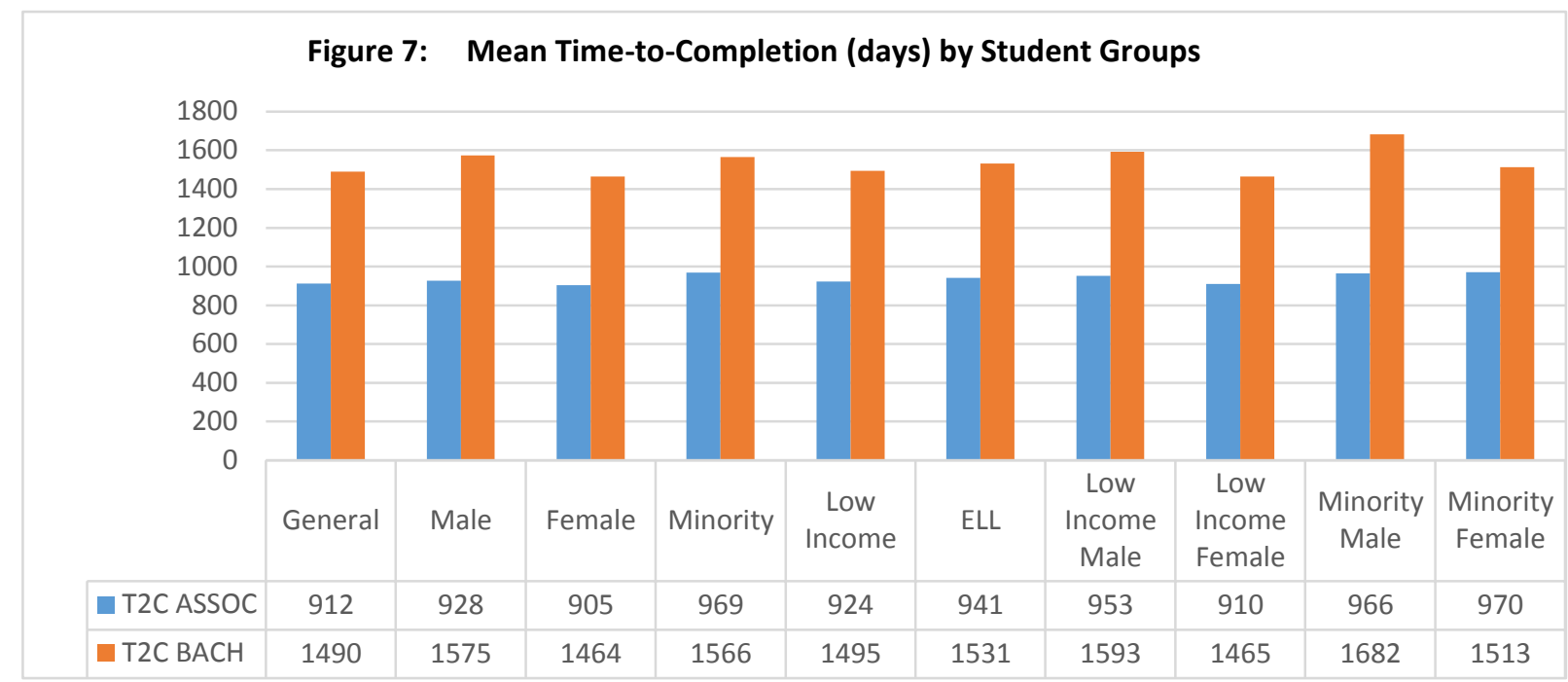

\section{Methodology}

To estimate the effects of DCE and ECHS, this study employs Propensity Score Matching (PSM) as an alternative to standard linear regression estimation forms, such as OLS and GLS, in support of assessing causal inference (Abadie \& Imbens, 2012; Dehejia \& Wahba, 2002; Peikes, Moreno \& Orzol, 2012; Rosenbaum \& Rubin, 1983, 1984, \& 1985). PSM is used extensively to support causal inference in education studies, including those related to DCE and ECHS (An, 2009; Schneider et al, 2007; Speroni, 2011; Struhl \& Vargas, 2012; Taylor, 2013). The method provides a quasi-experimental design structure for non-experimental studies in which a prescribed treatment is applied to a portion of the study participants via non-randomized participation resulting in endogeneity or self-selection bias (Eide \& Showalter, 2012). Matching occurs through the selection of available pre-treatment independent variables, such that matched pairs are observable, distinguishable by their treatment selection. The average treatment effects are measured for the sample population and are then compared to the average treatment effect on the treated (ATET). When relevant differences between any two units are captured in the observable (pre-treatment) covariates, which occurs when outcomes are independent of assignment to treatments conditional on pretreatment covariates, matching methods can yield an unbiased estimate of the treatment effect. Where treatments are applied via self-selection, or in a non-experimental manner, there is no reasonable way to discern what outcomes may have occurred had the treatment not been applied: the counterfactual (Morgan \& Wanship, 2007).

From a theoretical standpoint, the way to obtain a counterfactual is to use the same participants under both treatment and control conditions, restoring internal and external conditions to initial values present before participants encountered either. As such, participant outcomes are observed under the treatment (factual) and the control condition (counter-factual), and the difference in outcomes is the individual treatment effect. Averaging individual treatment effects for both groups and then subtracting those average from the quantified outcome (observed or estimated) yields the average treatment effect (Murnane \& Willett, 2011, p. 33-34). However, resetting internal and external conditions isn't feasible in social science research and as such, it is virtually impossible to obtain the outcome value of the control condition for individuals in the treatment group and it similarly lacks feasibility to obtain the outcome value of the treatment for individuals in the control group. Since observing or identifying counterfactual data isn't feasible in social science research there will always be missing data when calculating the average treatment effects (Holland, 1986; Murnane \& Willett, 2011; Shadish, Cook, \& Campbell, 2002).

\subsection{Estimation Models}

PSM analytics are not strictly regression estimates, but use probit or logit forms to compute the propensity score, which are simply probabilities. If the outcome is continuous, the effect of treatment can be estimated as the difference between the mean outcome for treated subjects and the mean outcome for untreated subjects in the matched sample (Rosenbaum \& Rubin, 1983, 1984 \& 1985). If the outcome is binary, the effect of treatment can be estimated as the difference between the proportion of subjects experiencing the event in each of the two groups (treated versus untreated) in the matched sample. As such, the reporting of treatment effects can be done using the same metrics as are commonly used in randomized control treatments. The estimates report with coefficient, standard error, $P$ value, and confidence intervals as do regression estimates, but include a calculated z-score rather than a $t$ statistic to aid in inferring statistical 
significance and do not include an $r$ squared value suggestive of the level of the model's fit.

As this study considers several potential outcomes for each of two Utah public high school graduation cohorts and separately examines the effects of two unique and one combined treatment on each, the organization of the estimation models is relatively complex, even though the models themselves appear to be as simple as $Y=\beta_{1}$ treatment $+e$. This model is estimated for each match in the covariate set and it is only then that a coefficient, standard deviation, $\mathrm{z}$-score, probability, and confidence intervals are determined.

\subsection{Receiver Operating Characteristic (ROC) Analysis}

As outcomes based on PSM methods may vary depending on the selection of pretreatment variables and adjustment mechanisms internal to the methodology's models (nearest neighbor, caliper, and tolerance form ${ }^{22}$ ), Receiver Operating Characteristic (ROC) Analysis is used in this study to identify and employ an accurate model given the available variables and possible adjustments. ROC analysis quantifies the accuracy of diagnostic tests or other evaluation modalities used to discriminate between two states or conditions, allowing the discriminatory accuracy of a diagnostic test to be measured by its ability to correctly classify known subjects (Eng, 2005; Fawcett, 2006; Metz, 1978). The optimal model among these choices isn't necessarily the model offering the largest coefficients, but the model yielding the most accurate outcomes.

ROC analysis is built on a framework in which a cluster of analyses is examined with the cluster's estimated outcomes being compared to the observed outcomes such that sensitivity and specificity values between zero (0) and one (1) may be assigned each cluster (Eng, 2005; Fawcett, 2006; Metz, 1978). Sensitivity, also referred to as the true positive rate the ratio of true positives to total positives, and specificity is the ratio of true negatives to false positives plus true negatives. As false positives plus true positives equal one (1) or 100\%, specificity is also referred to as 1-false positive rate.

As PSM models are built around a treatment as a binary state with a binary outcome, ROC's use of sensitivity and specificity is well aligned with the analytical method. However, where continuous outcome variables are present the potential outcomes must be separated into binary groups, otherwise the application of ROC analysis isn't feasible (Eng, 2005; Fawcett, 1978; Metz, 1978).

As this particular model, one of many in this study, may be used to examine student outcomes based on a combination of eight pretreatment variables and three Nearest Neighbor match levels, there are nearly 241,000 possible models available, each separable into clusters resulting in separate combinations of sensitivity and specificity, with each combination forming a point on a ROC curve and yielding an area under the curve (AUC).

For this study we include three high school performance variables (CRT scores for Science, Language Arts, and Algebra I) in each model variation and select combinations of Gender, Minority, Income, Mobile, ELL and Nearest Neighbor match in 10 model variations (Appendix $\mathrm{A}^{\mathbf{2 3}}$ ) resulting in different values for each area under the curve (AUC) and yielding separate ROC curves for each model such that a set of ROC curves may be plotted revealing the optimal model - the model with greatest AUC.

\section{General Student Population Outcomes}

This section considers the effects of DCE and ECHS as treatments, both separately and collectively, with respect to the General Population of students in the Utah high school graduation cohorts of 2008 and 2009. The results are considered in three different groupings: 1) high school graduation and performance, 2) postsecondary higher education enrollment and graduation measurements and 3) degree attainment and time-to-completion, in each case taking treatments individually for DCE and ECHS. In the case of the high school graduation and performance, and postsecondary higher education enrollment each of the targeted cohorts is measured separately. This is the result of participation in high school being historical for the subject students, and an expectation that most of those students who are likely to enroll in higher education will have already done so, as the data for this study are collected and reported some 4 to 6 years after their high school graduations (Gold \& Albert, 2006; Scott, Bailey, \& Kienzl, 2006). All other outcome variables are measured for each individual cohort reflective of the ongoing higher education experience of many of these students. In several cases ( $<1 \%$ of the outcomes) the Propensity Score Match returned an overlap assumption error. Each of the

\footnotetext{
${ }^{22}$ Nearest Neighbor, Caliper, Tolerance and Form are adjustable specifications used in propensity score matching. Nearest Neighbor specifies the number of matches per observation, Caliper specifies the maximum distance at which two observations are a potential match. Tolerance specifies the minimum acceptable propensity score to be included. STATA's default parameters include Nearest Neighbor: 1; Caliper: all observations are potential matches regardless of how dissimilar they are; Tolerance: 1e-5; Form: Probit.

${ }^{23}$ Appendix A: Receiver Operating Characteristic (ROC) Analysis Matrix: www.richardhaskell.net/resources/Appendix+A+-+ROC+Analysis.pdf
} 
examined outcomes are statistically significant below the $1 \%$ level except as noted.

\subsection{High School Graduation and Performance}

The measurements of DCE and ECHS with respect to high school graduation and performance include variables representing K12 graduation (binary) and ACT test score measures for the Composite, Math, Reading, English and Science test scores (continuous).

K12 Graduation (Figure $8^{24}$ ): This examination estimates the effects of DCE and ECHS on high school graduation experience. As presented in Appendix $\mathrm{B}^{25}$, coefficients for estimates for high school graduation range from 0.198 to .247. The ATET for DCE and ECHS result in increased probabilities of high school graduation for the treated population of $19.8 \%$ to $24.7 \%$. Interestingly, there is no substantial difference between the effects of the differentiated treatments. K12 graduation rates in the state of Utah, already high in relation to other states generally (Greene \& Forster, 2003), are particularly high in relation to state level per pupil expenditures. The estimates for K12 Graduation present improvements for each treatment variant ranging from a low average treatment effect on the treated of $19.8 \%$ for ECHS students in the 2009 cohort to a high of $24.7 \%$ for DCE students in the 2008 cohort.

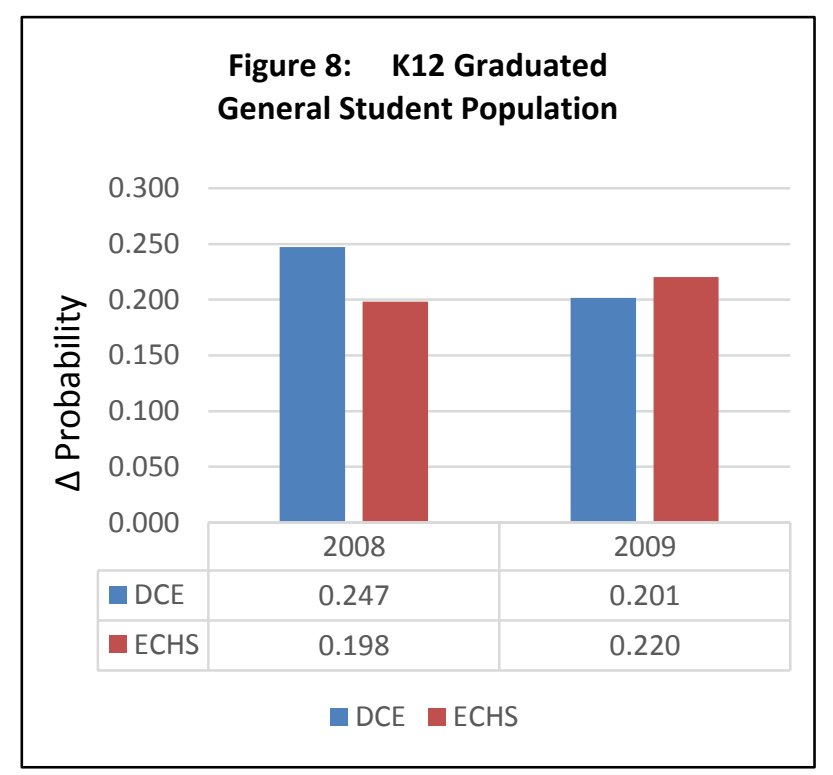

\subsection{Postsecondary Higher Education Enrollment and Graduation Measurements}

The measurements of DCE and ECHS with respect to postsecondary higher education enrollment and higher education graduation include measures for inside and outside of Utah higher education. Postsecondary higher education enrollment is measured rather than higher education enrollment generally as dual-credit enrollees experience higher education enrollment while in high school. Further, postsecondary higher education in Utah public education is measured separately from postsecondary higher education generally in an effort to determine the effects of the treatment with respect to the Utah higher education system and its outcomes, as well as the treatment outcomes generally. Higher education graduation is likewise separated into Utah higher education specific outcomes and higher education graduation outcomes generally by measuring the ATET with respect to any higher education graduation, irrespective of degree attainment, for students in the target cohorts.

Postsecondary Higher Education Enrollment - Utah (Figure $9^{26}$ ) includes Utah higher education enrollments by students in the targeted cohort. The estimations were consistently positive, with coefficients ranging from 0.268 to 0.392. The ATET for DCE and ECHS each reflect increased probabilities of postsecondary higher education enrollment of $26.8 \%$ to $39.2 \%$. There is a substantial difference in the effects of the differentiated treatments as the highest treatment effect for DCE students $(0.288$ for the 2008 cohort) is less than the smallest treatment effect for ECHS students ( 0.327 for the 2009 cohort). Though both offer positive changes in the probability of a student's postsecondary higher education enrollment, ECHS participation increases the probability of postsecondary higher education

${ }^{24}$ Figure 8: Utah Data Alliance; 2008 \& 2009 Public High School Graduation Cohorts, 2013 data release

${ }^{25}$ Appendix B: Propensity Score Matching (PSM) Analytic Tables:

www.richardhaskell.net/resources/Appendix+B+-+PSM+Panels.pdf

${ }^{26}$ Figure 9: Utah Data Alliance; 2008 \& 2009 Public High School Graduation Cohorts, 2013 data release 
enrollment by $22.1 \%$ over DCE. ${ }^{27}$ These results were generally expected given ECHS's aim of easing the transition between high school and higher education. It likely also speaks to an investment effect as ECHS students accumulate more higher education credits than do DCE enrollees.

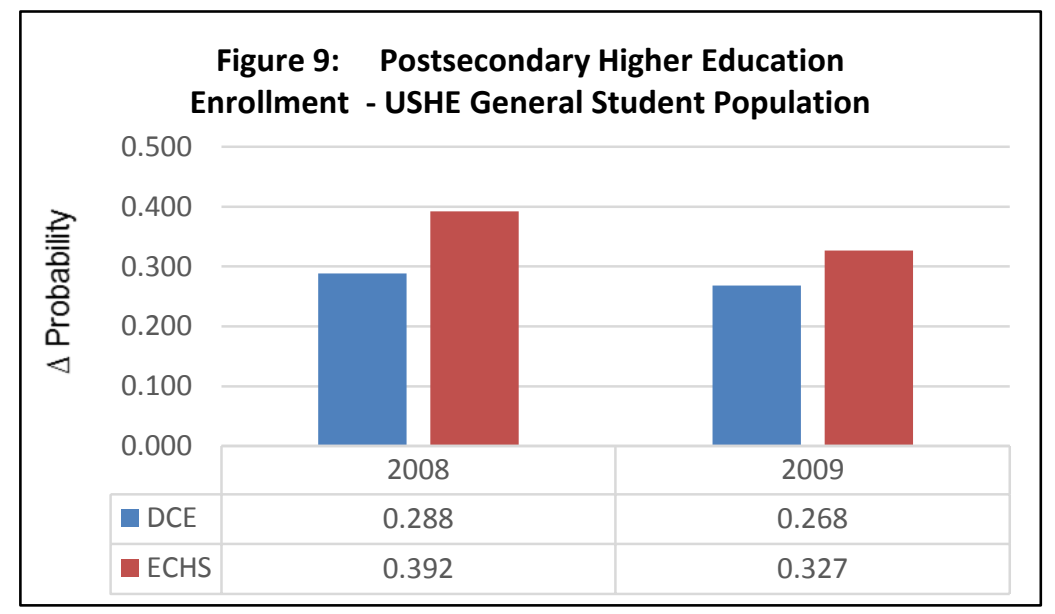

Postsecondary Higher Education Enrollment - All (Figure $10^{28}$ ) includes all higher education enrollments by students in the target cohorts through inclusion of select National Student Clearinghouse data (NSC) in the UDA data set. The estimates were consistently positive with coefficients ranging from 0.223 to 0.310 . ATET for both DCE and ECHS evidence increased probabilities of postsecondary higher education enrollment of $22.31 \%$ to $31 \%$.

There is a substantial difference in the effects of the differentiated treatments effects as the highest DCE treatment effect (.253 for the 2008 cohort) is less than the smallest treatment effect for ECHS students (.268 for the 2009 cohort). Though each offer positive changes in the probability of a student's postsecondary higher education enrollment, ECHS participation increases the probability of postsecondary higher education enrollment by $21.4 \%$ over DCE. ${ }^{29}$

The difference in probabilities between postsecondary higher education enrollments for Utah higher education as compared to all higher education was unexpected. The average probability of DCE enrollees attending Utah higher education was an increase of $16.8 \%{ }^{30}$ compared to $24.2 \%{ }^{31}$ observed for ECHS participants. Critics of these programs suggest participants are more likely to attend high profile and private higher education than public institutions owing both to the attractiveness of program graduates to these institutions and the institution's attraction to students. Though not specifically examined, the results suggest public higher education is a more attractive alternative to DCE and ECHS participants, potentially due to the investment program participants have in accumulated credits in Utah higher education, which credits may suffer reductions upon transfer to out-of-state and private institutions. Additionally, the existence of Utah's New Century Scholarship (Bracco \& Martinez, 2005; Kearl, 2012) may also be a determinant in this relation. Utah public education students earning an Associate's Degree coincident with receiving their high school diplomas may qualify for scholarship funding to pay for as much as $75 \%$ of their remaining higher education tuition expense at any Utah higher education institution. ${ }^{32}$

\footnotetext{
27 This percentage change was derived by averaging the effects for each of the treatments and then applying the percentage change formula: $\frac{E C H S-D C E}{D C E}(100)=\frac{0.339-0.278}{0.278}(100)=22.1 \%$

${ }^{28}$ Figure 10: Utah Data Alliance; 2008 \& 2009 Public High School Graduation Cohorts, 2013 data release

${ }^{29}$ This percentage change was derived by averaging the effects for each of the treatments and then applying the percentage change formula: $\frac{E C H S-D C E}{D C E}(100)=\frac{0.289-0.238}{0.238}(100)=21.4 .7 \%$

${ }^{30}$ This percentage change was derived by averaging the effects for each of the treatments and then applying the percentage change formula: $\frac{D C E(U T)-D C E(A L L)}{D C E(A L L)}(100)=\frac{0.278-0.238}{0.238}(100)=16.8 \%$.

31 This percentage change was derived by averaging the effects for each of the treatments and then applying the percentage change formula: $\frac{E C H S(U T)-E C H S(A L L)}{E C H S(A L L)}(100)=\frac{0.359-0.289}{0.289}(100)=24.2 \%$.

${ }^{32}$ The New Century Scholarship award levels and school applicability experienced changes during the targeted cohort years and may affect different cohort year students differently.
} 


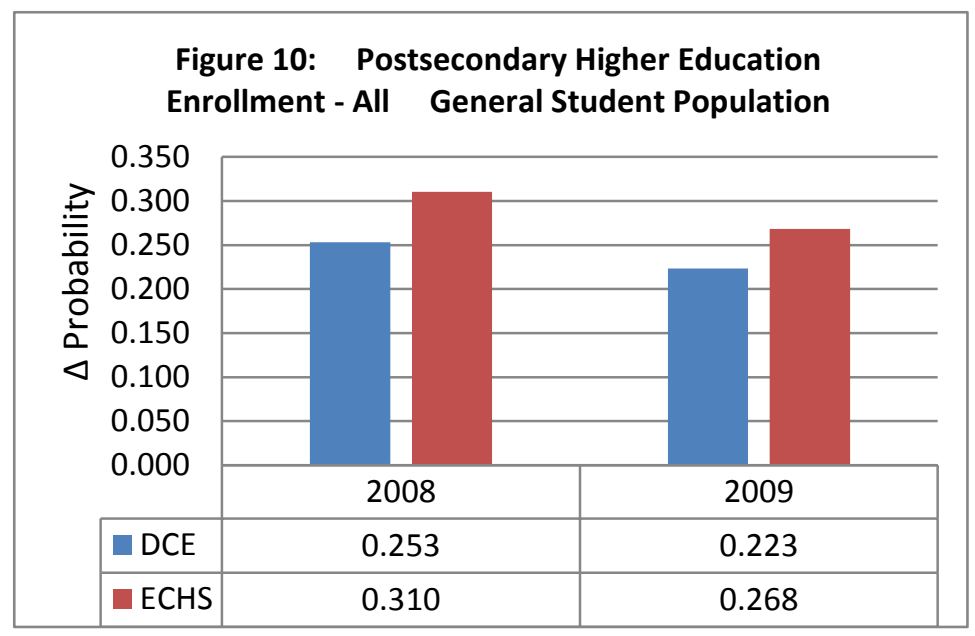

Higher Education Graduation - Utah (Figure 1133): The data for Higher Education Graduation - Utah in this study include all higher education graduations from institutions associated with the Utah System of Higher Education (USHE), including various certificate, Associate, Bachelor and graduate degrees, and reports as a binary variable, regardless of the number of graduations any particular student may have. The analysis is exclusive to graduations from Utah higher education and does not include higher education graduations, public or private, outside of those institutions overseen by USHE. The estimates represent the ATET for Utah higher education graduation for those students who enrolled in Utah higher education after the completion of high school and do not include data on those who did not enroll.

The coefficients for this measure are consistently positive and range from 0.084 to .429 . The ATET for DCE and ECHS reflect increased probability of higher education graduation of $8.4 \%$ and $42.9 \%$ compared to those who did not participate in the treatment. There is a substantial difference in the effects of the differentiated treatments with largest effect of DCE (0.084) being substantially less than the smallest effect of ECHS (0.402).

Of interest in this outcome panel is the difference in ATET based on the applied treatment. ECHS participation resulted in an increase in Utah higher education graduation of $40.2 \%$ and $42.9 \%$ for the 2008 and 2009 high school graduation cohorts, respectively, as compared to the ATET for DCE $8.4 \%$ and 59\%. A substantial portion of this difference is the result of the high level of ECHS participants earning an Associate's Degree coincident with their high school graduations.

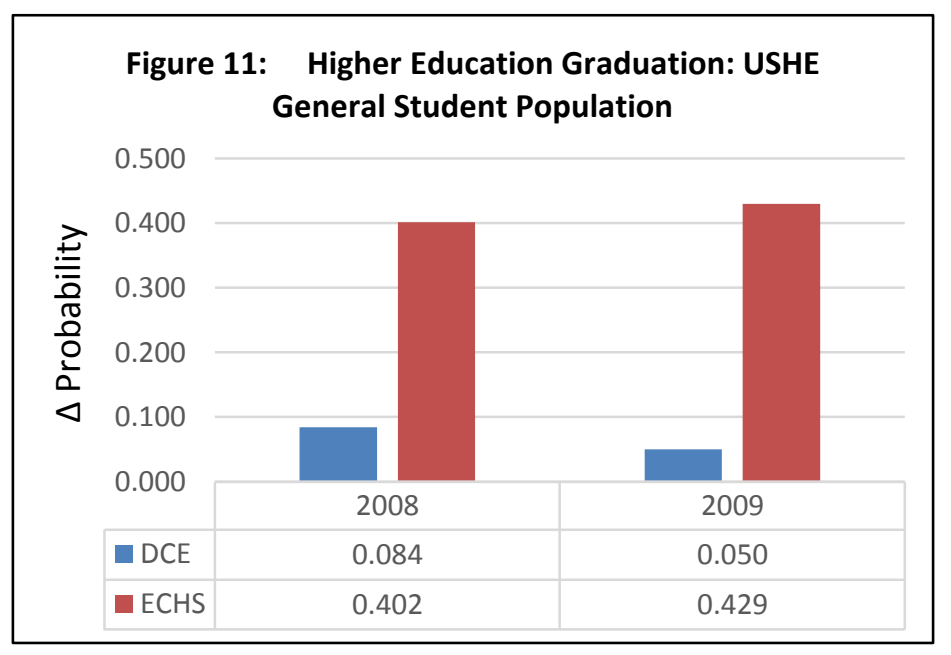

Higher Education Graduation - All (Figure $12^{34}$ ): The data for Higher Education Graduation - All in this study include all higher education graduations from all higher education institutions regardless of the state in which the institution is located or its public/private nature. The examination includes various certificate, Associate, Bachelor's and graduate

33 Figure 11: Utah Data Alliance; 2008 \& 2009 Public High School Graduation Cohorts, 2013 data release

${ }^{34}$ Figure 12: Utah Data Alliance; 2008 \& 2009 Public High School Graduation Cohorts, 2013 data release 
degrees, and reports as a binary variable, regardless of the number of graduations any particular student may have. The coefficients are consistently positive and range from 0.147 to .441. The ATET for DCE and ECHS each reflects increased probabilities of higher education graduation of $14.7 \%$ and $44.1 \%$ when compared to non-participation in the respective treatment. There is a substantial difference in the effects of the differentiated treatments with the largest effect of DCE (0.223) being substantially less than the smallest effect of ECHS (0.36). ECHS participation results in an increase in Utah higher education graduation of 36\% and 44.1\% for the 2008 and 2009 high school graduation cohorts, respectively, as compared to the ATET for DCE $14.7 \%$ and 22.3\%, respectively. A substantial portion of this difference is the result of the high level of ECHS participants earning an Associate's Degree coincident with their high school graduations.

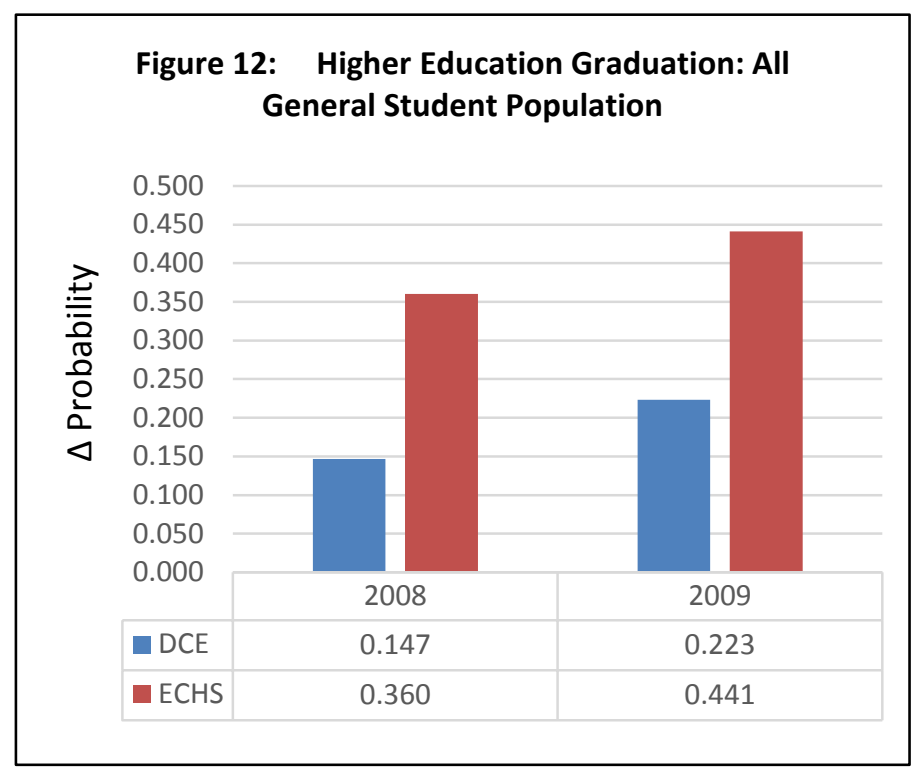

\subsection{Time-to-Completion}

This examination reveals the effects of DCE and/or ECHS on higher education time-to-completion (Associate's and Bachelor's) for those students who enrolled in, and subsequently graduated from, Utah higher education, specifically from those institutions overseen by the Utah System of Higher Education(Figures $13^{35}$ and $14^{36}$ ). Time-to-Completion for a Master's is not estimated due to the low number of these degrees earned by students in the targeted cohorts. Time-to-completion is the number of days between public high school graduation and graduation from Utah higher education. A positive outcome is reported as a negative value and gauges the temporal benefit obtained as a result of participating in the target treatments.

Each of the nine estimations for time-to-completion: Associate's degree is consistently negative and range from -851.66 and -262.3. The ATET for DCE and ECHS each provide a negative effect on the number of days between high school and higher education graduation with an Associate's Degree of 262.3 and 851.66 days when compared to those who did not participate in treatment. There is a substantial and expected difference in the effects of the differentiated treatments with the largest effect of DCE (-266.12) being 571.67 days less than the smallest effect of ECHS (-837.79). This effect is, in part, a reflection of the structure and goal of the ECHS treatment as its participants are provided a pathway towards earning an Associate's Degree coincident with high school graduation. Such an advantage would result in a decrease in time-to-completion of as many as 730 days, all else being equal.

Each of the four estimations for time-to-completion: Bachelor's degree represents a negative correlation between treatment participation and time-to-completion with ATET values for DCE and ECHS of -167.04 and -316.94 . The coefficients for the DCE treatment being -167.04 and -188.94 for the cohorts, respectively, while the ECHS treatment is -249.17 and -316.94 . This effect may, in part, be a reflection of course availability and course requirements for any given major in Utah higher education. It may also be reflective of a potential lack of preparation high school students may experience in selecting a higher education major and then selecting dual-credit enrollment courses to be applied to that major 2 or more years in their futures.

\footnotetext{
35 Figure 13: Utah Data Alliance; 2008 \& 2009 Public High School Graduation Cohorts, 2013 data release

${ }^{36}$ Figure 14: Utah Data Alliance; 2008 \& 2009 Public High School Graduation Cohorts, 2013 data release
} 

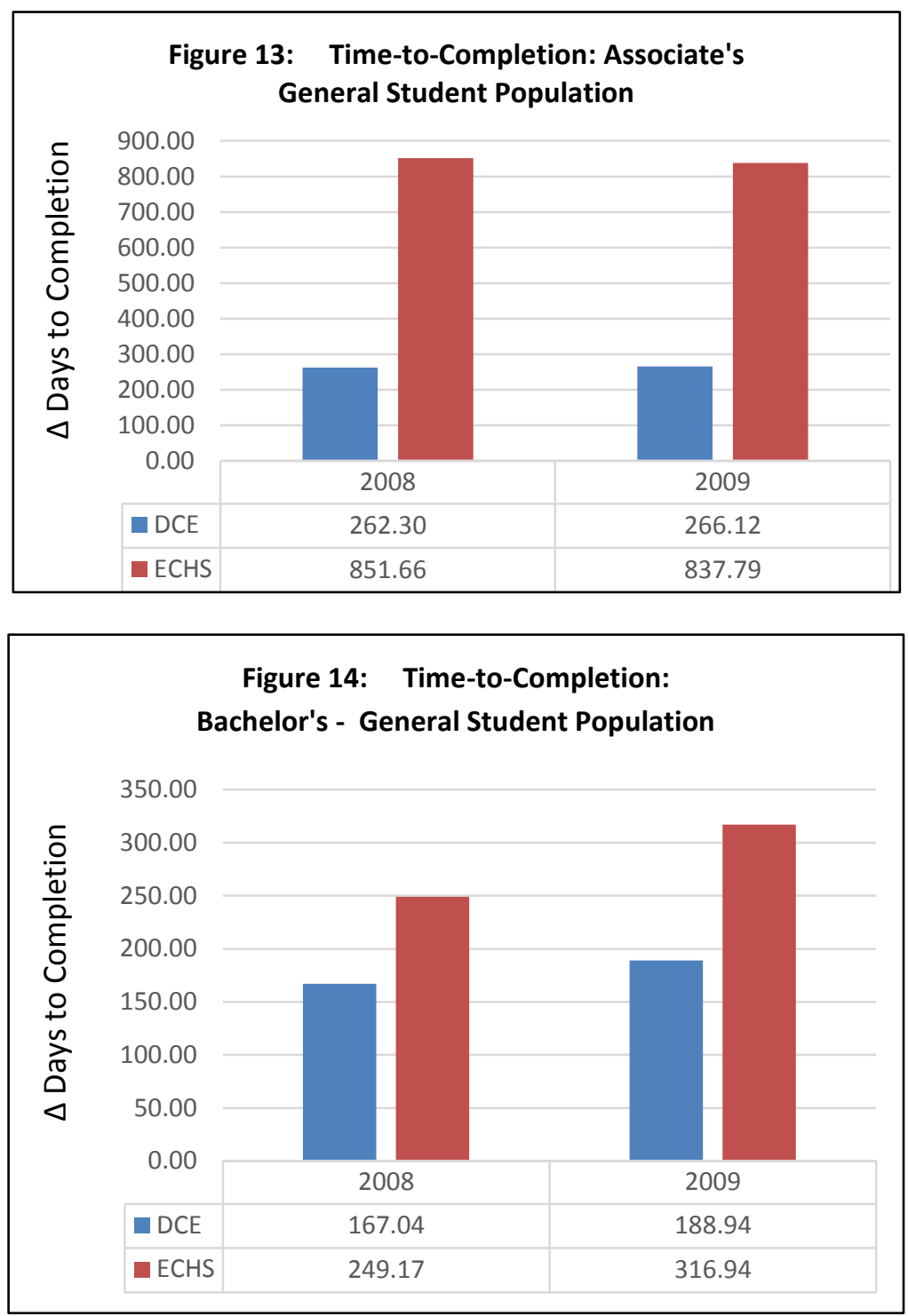

\section{Conclusion and Policy Considerations}

The success and growth of dual-credit enrollment programs to date have brought them into sharp focus for policy makers, but until recently the data to objectively assess their relative levels of success has been limited (Taylor, 2013; Smith, 2007; Swanson, 2008). With the release of the Utah Education Longitudinal Data, and similar data sets like it in other states, we're only now beginning to separate the effects of DCE from those of ECHS with respect to high school and higher education outcomes. An analysis of labor market outcomes, which many hold as the true test of these programs, remains at least several years away as the first high school graduates from these differentiated programs only recently began to graduate from higher education.

Clearly, student success is a function of numerous inputs, of which formal education comprises an important part. Influential household level attributes such as parental and sibling education, household composition, social networks and student intellect form what we might refer to as household endowments with respect to education, but these neither negate nor discount the import of education policy with respect to student success (Bragg, Kim \& Rubin, 2005). The available Utah data include variables specifically related to education policy with only a limited number of demographic and socio-economic variables to aid us in matching students and considering the effects of the students' household endowments on high school and higher education outcomes. However, as we examine student outcomes these variables, combined with those which measure specific outcomes, are sufficiently important to render the analysis meaningful, if not perfect (Bailey \& Kienzel, 2006; Taylor, 2013).

This study has shown that dual-credit enrollment programs yield varying levels of improvements in the probability of 
high school graduation, post-secondary higher education enrollment, and higher education graduation and degree attainment. These positive correlations suggest such programs, when analyzed as treatments on student populations, aid in improving the student condition and preparing students for their next steps into society and the markets. Where DCE and ECHS participation improve students' probability of high school graduation by an average of $27.4 \%$ and improve post-secondary higher education enrollment by $30.7 \%$ and $35.7 \%$ respectively, they set the stage for improved rates of higher education completion and degree attainment, resulting in state and household level financial and economic impacts. DCE's relationship between program participation and Utah public higher education graduation averaged $4.5 \%$ for the targeted high school graduation cohorts and while this may seem to be a small marginal effect, the impact on the 90,642 student in these cohorts could result in nearly 4,100 additional higher education degree holders in the state. Similar measures for Early College High School students, with gains in the probability of Utah public higher education graduation of $35 \%$, may yield multiples of that value.

Similarly, the effects of dual-credit enrollment program participation on dual course credits earned and higher education time-to-completion are clear. Without DCE and ECHS programs the opportunity to earn these higher education credits and decrease time-to-higher education completion simply would not exist. However, not all students are interested in participating in dual-credit enrollment programs, and were any given state to attempt to include all high school students in either of these programs the effective gains may diminish. But for those who do participate, the gains may yield life changing benefits. As such, motivating greater student participation in these programs through strategic expansion of both DCE and ECHS offerings stands to yield important benefits to the state and student households.

While it may be difficult to measure the particular economic effects of most of the outcomes measured in this study, the economics of providing higher education credit hours during high school versus while enrolled in higher education is relatively straight forward, as may be the temporal benefit resulting from the decreased time-to-completion due to dual-credit enrollment programs (Hunt, 2007; Karp, Bailey \& Hughes, 2005).

During the academic year 2009-2010, the State of Utah allocated \$6,165,271 for Advanced Placement and Concurrent Enrollment programs at the public high school level, resulting in 194,614 higher education credits earned by 28,185 students; an average of 6.9 credit hours for each participating student at a cost of $\$ 218.74$ per student or $\$ 31.70$ per credit hour. Had these students enrolled in the same number of credit hours at Salt Lake Community College ${ }^{37}$ during the same year, the per unit cost based on a full-time-equivalence of 14 credit hours at a cost of $\$ 2,416$ per semester would have resulted in a combined cost to the state and household of $\$ 172.57$. The net effect of these students having the opportunity to earn higher education credit hours under dual-credit enrollment programs resulted in a combined state and household level cost savings of $\$ 140.87$ per credit hour for a total of $\$ 27,415,274.18^{38}$. Of this amount, households would have born $\$ 19,391,895^{39}$ in tuition expenses and the state would have born an additional $\$ 8,023,935^{40}$ over and above that which had already spent on these same students and credit hours at the high school level.

Low income and minority households, with fewer economic resources to expend on higher education, stand to experience greater gains from these savings than their better resourced counterparts (Bailey, Hughes \& Karp, 2003; Brand \& Lerner, 2006). Concern over rising levels of student loan debt has increased in recent years as the household higher education costs have risen. As race and gender based income and wealth disparities remain persistent, the effects of such debt may be particularly troublesome with respect to these student populations. Decreases in household level higher education costs under dual-credit enrollment programs potentially reduces student loan debt levels giving rise to longer-term benefits as household discretionary income increases due to lower levels of debt servicing. These affordability effects may be contributing factors to the improved probabilities these student groups experience with

${ }^{37}$ Salt Lake Community College is the affiliated college for most dual-credit enrollment courses in the state of Utah and is the state's largest community college.

${ }^{38}$ Calculation of total cost savings: Based on per academic year FTE at 14 credit hours and two semesters per year, the per year total cost of lower division education at Salt Lake Community College for 2009-2010 equates to $\$ 4,832$ or $\$ 2,416$ per semester; $\$ 172.57$ per credit hour. Given the $\$ 31.70$ cost per credit hour to USOE, this results in a cost savings of $\$ 140.87$ per credit hour and totals $\$ 27,415,274.18$ when multiplied my 194,164 credit hours.

${ }^{39}$ Calculation of household level savings: Based on per semester full time tuition and fees at Salt Lake Community College for academic year 2009-2010 of $\$ 1,395$ and 14 credit hours per semester, the per credit hours cost equals $\$ 99.64$. Multiplied by 194,614 credit hours, this equals $\$ 19,391,895$.

${ }^{40}$ Calculation of state level savings: Based on the calculated cost savings of $\$ 140.87$ per credit less the household contribution of $\$ 99.64$ per credit, the state's additional cost of supporting these students as Salt Lake Community College students during the 2009-2010 academic year, over and above that which the state already contributed through supporting the cost of these students and credit hours at the high school level, equates to $\$ 41.23$. Multiplied over 194,614 units, the state savings equates to $\$ 8,023,935.22$. 
respect to post-secondary higher education enrollment and higher education completion and degree attainment.

The benefits of reduced time-to-completion arising from dual-credit enrollment programs potentially include increased rates of labor force participation as students benefiting from these programs stand to enter the workforce at younger ages and with greater probabilities of increased levels of higher education completion and degree attainment (Johnstone \& Del Genio, 2001). This may be especially impactful for students entering the increasingly competitive job markets following the 2007-2009 recession; earning Bachelor's degrees with decreased time-to-completion of 255 and 445 days for DCE and ECHS respectively. The present and future value of these improvements are a function of discount and employment rates, income levels, and retirement ages of course, and as such may be difficult to quantify at the beginning of a student's career. However, the gains may offer important economy wide contributions through increased levels of household demand, local, state and federal tax revenues.

The gains dual-credit enrollment participants experience in time-to-completion at the Associate's degree level appear to dissipate for those students earning Bachelor's degrees. From 299 and 867 days of improved time-to-completion for an Associate's degree, low income student experience reflects declines of 131 and 213 days for DCE and ECHS, respectively. For those students who earn their Associate's degrees, a transfer degree in General Studies is the most commonly earned. These students tend to be 17-18 years of age and have little exposure to subject areas in which they may ultimately choose to major or plan a career, and as such the major selection for a four-year degree often includes falling back and taking courses that might have been taken in years one or two of their higher education experience or making course corrections during their third and fourth years. Depending on the college or university from which the students select to earn their Bachelor's degree, some of these students find sufficient differences in course requirements that certain course credits do not transfer, or transfer at a lower credit rate, resulting in the need to retake courses or simply taking more courses than otherwise expected. Yet other students lack the emotional maturity and perspective necessary to make long-term education decisions or simply take time away from higher education, voluntarily spending down some of the advantage gained (Speroni, 2010; Venezia, Kirst \& Antonio, 2003). In any event, much of the temporal advantage gained through dual-credit enrollment participation is lost for many of these students, effectively decreasing though not eliminating, important benefits gained from these programs.

Perhaps the most enduring benefit of participation in dual-credit enrollment programs involves the household endowment effect with respect to education. We sometimes forget that gains from education policy often occur over decades and while they may also be reflected in the productivity of any given student or worker, their most meaningful impact may be experienced generations in the future. Our society's current focus on post-secondary or higher education completion is made possible by the high school movement of the early $20^{\text {th }}$ century, prior to which only higher performing or economically advantaged students participated in secondary education. Similarly, it wasn't until the latter part of the same century that higher education began to become accessible to the masses. The public policy resulting in these advancements in human capital investment not only set the stage for the golden age of capitalism, but also led to household level endowments motivating yet higher levels of investment for future generations. In similar fashion, as dual-credit enrollment programs, the roots of which may be found in the early 1970's, result in higher rates of educational participation and attainment, they set the stage for future generations of households with higher incomes, parents whose college degrees form expectations for their children, and young people with the preparation and perspective to reach for greater levels of innovation and productivity.

\section{Acknowledgements}

This study was made possible by the generous support of the Marriner S. Eccles Foundation, and cooperation of the Utah Data Alliance and its stakeholders: the Utah State Office of Education, Utah System of Higher Education, Utah College of Applied Technology, Utah Education Network, Utah Department of Workforce Services, and the Utah Education Policy Center.

\section{References}

Abadie, A., \& Imbens, G. W. (2012). Matching on the estimated propensity score. NBER Working Papers, (December 2012), 1-36.

An, B. (2009). The impact of dual enrollment on college performance and attainment (Published doctoral dissertation). University of Wisconsin-Madison, Madison, WI.

Appleby, J., Ashton Ferrell, K., Gesing, E., Jackson, S., Linder, Ti., Mata, S. Shelnutt, A., \& Wu, Y. (2011). A study of dual credit Access and Effectiveness in the State of Texas, Bush School of Government and Public Service, Texas A $\& \mathrm{M}, 2011$.

Austin, P. C. (2011). An introduction to propensity score matching methods for reducing the effects of confounding observational studies. Multivariate Behavioral Research, 46, 399-424. http://dx.doi.org/10.1080/00273171.2011.568786 
Bailey, T., \& Karp, M. M. (2003). Promoting college access and success: A review of credit-based transition programs. Washington DC: US Department of Education, Office of Vocational and Adult Education.

Bailey, T., Hughes, K., \& Karp, M. M. (2003). Dual enrollment programs: Easing transitions from high school to college. Community College Research Center Brief, March, 1-4.

Berger, A., Turk-Bicaki, L., Garet, M., Song, M., Knudsen, J., Haxton, C., \& Stephan, J. (2013). Early college, early success. American Institutes for Research, (June 2013), 1-130.

Boswell, K. (2001). State policy and postsecondary enrollment options. New Directions for Community Colleges, 113(Spring), 1-10.

Bragg, D. D., Kim, E., \& Rubin, M. B. (2005). Academic pathways to college: Policies and practices of the fifty States to reach underserved students. Office of Community College Research Leadership, Department of Educational Organization and Leadership, University of Illinois at Urbana-Champaign.

Brand, B., \& Lerner, J. B. (2006). The college ladder: Linking secondary and postsecondary education for success for all students. American Youth Policy Forum, Washington DC.

Dehejia, R. H., \& Wahba, S. (2002). Propensity score matching methods for nonexperimental causal studies. The Review of Economics and Statistics, 84(1), 151-161. http://dx.doi.org/10.1162/003465302317331982

Edmunds, J. A., Berstein, L., Glennie, E., Willse, J., Ashavsky, N., Unlu, F., \& Dallas, A. et al. (2010). Preparing students for college: The implementation and impact of the Early College High School. Peabody Journal of Education, 85, 348-364. http://dx.doi.org/10.1080/0161956X.2010.491702

Eide, E. R., \& Showalter, M. H. (2012). Methods matter: Improving causal inference in educational and social science research - a review article. Economics of Education Review, 31, 744-748. http://dx.doi.org/10.1016/j.econedurev.2012.05.010

Eng, J. (2005). Receiver operating characteristic analysis: A primer. Academic Radiology, Johns Hopkins University, 12(7), 909-916. http://dx.doi.org/10.1016/j.acra.2005.04.005

Fawcett, T. (2006). An introduction to ROC analysis. Pattern Recognition Letters, 27, 861-974. http://dx.doi.org/10.1016/j.patrec.2005.10.010

Fincher-Ford, M. (1996). High school students earning college credit: A guide to creating dual credit programs. Corwin Press, Inc.

Greenberg, A. R. (1988). Concurrent enrollment programs: College credit for high school students. Fastback 284, Phi Delta Kappa Educational Foundation.

Harnish, D., \& Lynch, R. L. (2005). Secondary to postsecondary technical education transitions: An exploratory study of dual enrollment in Georgia. Career and Technical Education Research, 30(3), 169-188. http://dx.doi.org/10.5328/CTER30.3.169

Haskell, R. E. (2016). The effects of dual-credit enrollment on underrepresented students: the Utah case; International Journal of Economics and Finance, 8(1), 144-175.

http://www.ccsenet.org/journal/index.php/ijef/article/view/54041/0;

Holland, P. W. (1986). Statistics and causal inference. Journal of the American Statistical Association, 81(396), 945-960. http://www.schools.utah.gov/data/Superintendent-s-Annual-Report/AR-2009-2010.aspx http://dx.doi.org/10.1080/01621459.1986.10478354

Hunt, E. L. (2007). Dual funding for dual enrollment: An inducement or an impediment? Community College, Journal of Research and Practice, 31, 863-881. http://dx.doi.org/10.1080/10668920600857255

Johnstone, B. D., \& Del Genio, B. (2001). College level learning in high school: Purposes, policies and practical implications. The Academy in Transition, Association of American Colleges and Universities, Washington DC.

Karp, M. M., \& Hughes, K. L. (2008). Supporting college transitions through collaborative programming: A conceptual model for guiding policy. The Teachers College Record, 110(4), 838-866.

Karp, M. M., Bailey, T. R., \& Hughes, K. L. (2005). State dual enrollment policies: Addressing access and quality. Community College Research Center Brief, 26, 1-4.

Karp, M. M., Calcagno, J. C., Hughes, K. L., Jeong, D. W., \& Bailey, T. R. (2007). The postsecondary achievements of participants in dual enrollment: An analysis of outcomes in two states. Community College Research Center, Teacher's College, Columbia University, 1-83.

Kim, J., \& Bragg, D. (2008). The impact of dual and articulated credit on college readiness and retention in four 
community colleges. Career and Technical Education Research, 33(2), 133-158. http://dx.doi.org/10.5328/CTER33.2.133

Kirst, M. W., \& Venezia, A. (2006, March 10). What states must do. Retrieved from The Chronicle of Higher Education website: http://chronicle.com/weekly/v52/i27/27b03601.htm

Kleiner, B., \& Lewis, L. (April 2005). Dual enrollment of high school students at postsecondary institutions 2002-2003. National Center for Education Statistics, US Department of Education, NCES 2005-008.

Lieberman, J. E. (2004). The Early College High School concept: Requisites for success. The Early College High School Initiative, 1-6.

Martinez, M., \& Bray, J. (2002). All over the map: State policies to improve the high school. The Institute of Educational Leadership, Washington DC.

Metz, C. E. (1978). Basic principles of ROC analysis. Seminars in Nuclear Medicine, VII(4), 283-298. http://dx.doi.org/10.1016/S0001-2998(78)80014-2

Morgan, S. L., \& Winship, C. (2007). Counterfactuals and causal inference: Methods and principles for social science research. New York, NY: Cambridge University Press. http://dx.doi.org/10.1017/CBO9780511804564

Murnane, R. J., \& Willett, J. B. (2011). Methods matter: Improving causal inference in educational and social science research. New York, NY: Oxford University Press.

Nakkula, Michael, B. Richards, \& Ongaga (2010). “Oh... I'm going to graduate!” Adapting, Thriving and Leading in the First Two Years of College, University of Philadelphia, Graduate School of Education, 2010

Ongaga, K. O. (2010). Students' learning experiences in Early College High School. Peabody Journal of Education, 85, 375-388. http://dx.doi.org/10.1080/0161956X.2010.491708

Orr, M. T. (2002). Dual enrollment: Developments, trends and impacts. Presentation to the Community College Research Center, Teachers College, Columbia University, New York, New York.

Peikes, D. N., Moreno, L., \& Orzol, S. (2012). Propensity score matching. The American Statesman, 63(2), 222-231. http://dx.doi.org/10.11198/00031313008X332016

Rosenbaum, P. R., \& Rubin, D. B. (1983). The Central Role of the Propensity Score in Observational Studies for Causal Effects. Biometrica, 70(1), 41-55. http://dx.doi.org/10.1093/biomet/70.1.41

Rosenbaum, P. R., \& Rubin, D. B. (1984). Reducing bias in observational studies using sub-classification on the propensity score. Journal of the American Statistical Association, 79, 516-524. http://dx.doi.org/10.1080/01621459.1984.10478078

Rosenbaum, P. R., \& Rubin, D. B. (1985). Constructing a control group using multivariate matched sampling methods that incorporate the propensity score. The American Statistician, 39(1), 33-38.

Rothstein, J., \& Rouse, C.E. (2011), Constrained after college: Student loans and early career occupational choice, Journal of Public Economics, 95(1), 149-163

Schneider, B., Carnoy, M., Kilpatrick, J., Schmidt, W. H., \& Shavelson, R. J. (2007). Estimating causal effects using experimental and observational designs, Report from the Governing Board of the American Educational Research Association Grants Program. Washington DC: American Educational Research Association.

Scott, M., Bailey, T., \& Kienzl, G. (2006). Relative success? Determinants of college graduation rates in public and private colleges. Research in Higher Education, 47(3), 249-279. http://dx.doi.org/10.1007/s11162-005-9388-y

Serdyukov, P. (2008). Accelerated Learning: What is it?, Journal of Research in Innovative Teaching, 1(1), 35-59

Shadish, W., Cook, T. D., \& Campbell, D. T. (2002). Experimental and quasi-experimental designs for generalized causal inference. Boston, MA: Houghton Mifflin Company.

Smith, D. (2007). Why expand dual credit programs. Community College Journal of Research and Practice, 31, 371-387. http://dx.doi.org/10.1080/10668920600932884

Speroni, C. (2010). High school dual enrollment programs: Are we fast tracking students too fast? Association for Institutional Research Forum, Chicago, IL, April 30, 2010, 1-31.

Speroni, C. (2011). Determinants of students' success: The role of advanced placement and dual credit enrollment programs. National Center for Postsecondary Research, Teachers College, Columbia University.

Struhl, B., \& Vargas, J. (2012). Taking college courses in high school: A strategy for students' success: the outcomes of dual enrollment in Texas. Jobs for the Future, Retrieved from 
http://www.jff.org/sites/default/files/TakingCollegeCourses_101712.pdf.

Swanson, J. L. (2008). An analysis of the impact of high school dual enrollment course participation on postsecondary academic success, persistence, and degree completion (Unpublished doctoral dissertation). Graduate College of the University of Iowa, Iowa City, IA.

Taylor, J. (2013). Community College Dual Credit: Differential Participation and Differential Impacts on College Access and Completion (Unpublished doctoral dissertation). University of Illinois at Urbana-Champaign, Champaign, IL.

USOE (2013), Utah State Office of Education Yearbook 2013 (Utah State Office of Education, Comp.). Salt Lake City, UT: Utah State Office of Education.

Utah Administrative Rule R277-713, Concurrent Enrollment of High School Students in College Courses, H.R. R277-713, 2014 Leg. (Utah 2014).

Utah State Office of Education (USOE) revenue by district-LEA (Utah State Office of Education, Comp.). (2014, July 1). Salt Lake City, UT: Utah State Office of Education.

Utah System of Higher Education Data Book (2010). Summary of concurrent enrollment data (Utah System of Higher Education, Comp.). (2010). Salt Lake City, UT: Utah System of Higher Education. http://higheredutah.org/wp-content/uploads/2013/05/rd_2010_databook.pdf

Utah System of Higher Education Data Book (2011). Cost Study, Tab I, p. 31 (Utah System of Higher Education, Comp.). (2011). Salt Lake City, UT: Utah System of Higher Education. http://higheredutah.org/wp-content/uploads/2013/05/rd_2011_databook.pdf

Vargas, J. (2013). The economic payoff for closing the college-readiness and completion gaps. Early College Designs, Jobs for the Future.

Venezia, A., Kirst, M. W., \& Antonio, A. L. (2003). Betraying the college dream: How disconnected K-12 and postsecondary education systems undermine student aspirations. US Department of Education.

Welsh, J., Brake, N., \& Choi, N. (2005). Student participation and performance in dual-credit courses in a reform environment. Community College Journal of Research and Practice, 29, 199-205. http://dx.doi.org/10.1080/10668920590901158

\section{Copyrights}

Copyright for this article is retained by the author(s), with first publication rights granted to Applied Economics and Finance (ISSN 2332-7294; E-ISSN 2332-7308).

This is an open-access article distributed under the terms and conditions of the Creative Commons Attribution license (http://creativecommons.org/licenses/by/3.0/).

\section{$(\mathrm{cc})$ EY}

This work is licensed under a Creative Commons Attribution 3.0 License. 